\title{
USO DAS TECNOLOGIAS DE INFORMAÇÃO E COMUNICAÇÃO E DINÂMICAS DO TRABALHO DOCENTE
}

\author{
USE OF INFORMATION AND \\ COMMUNICATION TECHNOLOGIES \\ AND WORK DYNAMICS OF TEACHING
}

\author{
Tássio de Souza Damasceno ${ }^{1}$ \\ tassiosouzadamasceno@gmail.com \\ Denise Machado Cardoso ${ }^{2}$ \\ denise@ufpa.com.br \\ Lorena Tamyres Trindade da Costa ${ }^{3}$ \\ lotamyres.19@gmail.com
}

\section{RESUMO}

As Tecnologias de Informação e Comunicação (TIC) invadiram as salas de aula modificando completamente o cotidiano acadêmico, estabelecendo uma nova relação entre as tecnologias e a sociabilidade, configurando a cultura contemporânea. A partir disso, buscamos analisar como discentes e docentes do curso de Ciências Sociais da Universidade Federal do Pará (UFPA) têm utilizado essas novas tecnologias como, por exemplo, tablets, notebooks e smartphones, como ferramentas didáticas no processo de ensino dentro da sala de aula. O objetivo deste trabalho é identificar para que fins esses sujeitos estão utilizando essas ferramentas dentro da sala de aula e se existe a aplicação delas como auxiliares no ensino. A metodologia utilizada neste trabalho é baseada na pesquisa de campo, na qual foram utilizados instrumentos como roteiro de entrevista semiestruturada, a observação direta e participante e o registro em diário de campo. A partir dos resultados obtidos nessa pesquisa, podemos ressaltar uma série de processos provenientes da inserção e do uso de TIC dentro do contexto acadêmico e, principalmente, dentro da sala de aula. Dessa forma, destacamos as iniciativas didáticas e os conflitos na relação entre docentes e discentes referentes ao uso de TIC durante as aulas, bem como a tentativa da instituição em adaptar sua estrutura física para suprir as demandas provenientes do atual contexto da Sociedade da Informação.

Palavras-Chave:Tecnologias de Informação e Comunicação.Cibercultura. Educação.

\begin{abstract}
Information and Communication Technologies (ICT) are have invaded as classrooms completely changing academic everyday life, establishing a new relationship between technologies and sociability, shaping a contemporary culture. From thisHence, we sought students and teachers of the Science course of the Federal University of Pará (UFPA) sought to analyze it in order to obtain new technologies such as tablets, notebooks and smartphones.in class. Is this work we search for the purposes of the client in the teaching of the client?how these technologies have been used in classroom by them. The method selected in this work is based on direct, participatory and field-based
\end{abstract}


journaling. From the results obtained, it is possible to include a series of processes of insertion and use of ICT within the academic context and, mainly, within the classroom. Thus, we highlight the didactic initiatives and results achieved in the relationship between teachers and students about the use of ICT during classes, as well as the attempt to adapt to the physical infrastructure to meet the demands coming from the current context of the a Society stand out ofbased on Information.

Keywords: Information and Communication Technologies. Cyberculture. Education.

\section{INTRODUÇ̃̃O}

Uma das maiores características da contemporaneidade é, sem dúvidas, a presença cada vez maior de Tecnologias de Informação e Comunicação (TIC) em vários setores da nossa sociedade. De forma geral, TIC são todas as tecnologias que interferem e mediam os processos de informação e conhecimento entre os seres humanos. No caso deste trabalho, o que chamamos de TIC, são as novas tecnologias digitais e informáticas (computadores, notebooks, tablets,smartphones) que têm o acesso à internet como uma de suas várias funções. Essas novas tecnologias, quando conectadas entre si e à rede mundial de computadores, transformam-se em um sistema altamente integrado que é utilizado para gerir uma grande quantidade de processos e informações em diversos setores da sociedade.

Nas últimas décadas, com a difusão da internet e a rapidez das inovações tecnológicas, houve um processo crescente do uso dessas novas tecnologias por parte dos indivíduos para exercerem diversas atividades do dia a dia (comunicar-se, estudar, trabalhar, comprar). Nesse contexto, propomos a investigação sobre como vem se dando a utilização de TIC por docentes e discentes da Universidade Federal do Pará (UFPA), mais especificamente, no curso de Ciências Sociais. Assim, consideramos pertinente refletir sobre a integração de novas tecnologias no nosso cotidiano e como isso tem contribuído para um processo de ressignificação e remodelação de muitos dos nossos hábitos, valores e costumes, criando novas formas de trabalho, de sociabilidade, reconfigurando a cultura contemporânea.

Desse conjunto de descrição, podemos ressaltar os estudos realizados por Castells (2016), que apresentam importantes análises sobre a morfologia social das sociedades de tecnologia avançada no contexto da Sociedade da Informação. Nessa Sociedade da Informação, a informação e o conhecimento tornam-se matérias-primas essenciais para o processo de desenvolvimento capitalista. A partir desse contexto de valorização da informação e do conhecimento aliada a uma série de políticas neoliberais para a educação, as Instituições de Ensino Superior (IES) passam a ser vistas como locais de extrema importância para o desenvolvimento de novas tecnologias, produção de conhecimento científico, além, é claro, de formação de mão-de-obra qualificada para o mercado de trabalho. (BAUMAN, 2001; HARVEY, 2004; VESCE, 2008).

A inserção de TIC nos ambientes acadêmicos vem reconfigurando esses espaços, os processos de trabalho, de sociabilidades e de troca de saberes e conhecimento entre os indivíduos. Em relação ao trabalho docente, essas ferramentas têm gerado consequências diretas na execução de seus trabalhos. Passa-se a cobrar melhor formação técnica e pedagógica dos professores, além de renovação nos métodos e práticas de ensino desses profissionais para que eles estejam aptos e preparados para lidar com essa nova realidade social. Mas não só o trabalho dos docentes está sendo permeado pela máquina como também a relação deles com seus alunos. Sabemos que a relação entre esses dois atores sociais ocorre principalmente dentro da sala de aula (face a face), no contexto 
do ensino e da aprendizagem.Agora, no entanto, um novo cenário surge nesse processo: o Ciberespaço.(LÉVY, 2010).

Pierre Lévy (2010) classifica o Ciberespaço da seguinte forma:

O Ciberespaço (que também chamarei de "rede") é o novo meio de comunicação que surge da interconexão mundial dos computadores. $\mathrm{O}$ termo especifica não apenas a infraestrutura material da comunicação digital, mas também o universo oceânico de informações que ela abriga, assim como os seres humanos que navegam e alimentam esse universo. Quanto ao neologismo "cibercultura", especifica aqui o conjunto de técnicas (materiais e intelectuais), de práticas, de atitudes, de modos de pensamento e de valores que se desenvolvem juntamente com o crescimento do ciberespaço. (LÉVY, 2010, p. 17).

Lévy (2010) enxerga as TIC como grandes potencializadoras do processo educacional, graças a sua estrutura em rede que permite um amplo acesso à informação disponível no ciberespaço, aliada à capacidade que essas novas tecnologias possuem de integrar e ampliar os processos de comunicação entre os indivíduos na sociedade. Outro ponto importante destacado pelo autor, é que as TIC ampliam a capacidade cognitiva dos seres humanos (aumento da memória, percepção, imaginação), provocando dessa forma, "uma profunda mutação na relação com o saber". (LÉVY, 2010, p. 174). Todos esses fatores juntos geram grupos de comunicação em rede, comunidades virtuais, redes de informação e compartilhamento, contribuindo diretamente para o surgimento de uma inteligência coletiva.

As transformações tecnológicas vividas pelos sujeitos na contemporaneidade representam não só a inserção de equipamentos e técnicas, mas, fundamentalmente, têm provocado mudanças de ordens sociais, culturais, econômicas, educacionais e, principalmente, no mundo do trabalho, uma vez que, no atual momento, torna-se indispensável que o trabalhador possua competência para lidar com essas tecnologias. Considerando que o processo educativo se relaciona intimamente com o contexto social, surge a necessidade da formação de um novo sujeito, a ser constituído diante desta realidade, forçando assim, uma reflexão acerca da atuação do docente e da formação docente.

A partir disso, este trabalho possui como objetivo refletir sobre a inserção das TIC no trabalho dos docentes e na relação deles com os discentes nesse contexto. Este artigo é resultado de pesquisas realizadas no âmbito do projeto Redes Sociais e Formação Docente em Ciências Sociais, que tem como objetivo contribuir nesta problemática, buscando identificar as relações e a influência que as TIC têm no cotidiano dos docentes e discentes do curso de ciências sociais da Universidade Federal do Pará (UFPA) e sua importância na formação desses profissionais. Nossa proposta de estudo foi investigar de que modo as TIC estão presentes no cotidiano acadêmico, os locais de acesso, como acioná-las e quais dinâmicas elas proporcionam nas práticas de docentes e discentes.

A partir do estudo do caso específico do curso de Ciências Sociais da UFPA, pretendemos colaborar para a construção de um panorama mais geral de discussões acerca do uso de TIC no ensino superior presencial e suas consequências, considerando as dificuldades e vantagens encontradas no processo de inserção e adaptação a essas novas tecnologias. É importante demonstrar que essa pesquisa é de fundamental importância, pois o uso das novas tecnologias no ambiente acadêmico, na rotina de trabalho de docentes e, especificamente, na sala de aula e na relação entre professores e alunos em mídias sociais já é uma realidade que necessita ser levada em consideração no planejamento e implantação de políticas educacionais e na formação de professores e alunos, 
pois influencia diretamente nos processos de trabalho, de sociabilidade entre esses sujeitos e na relação de ensino e aprendizagem entre eles.

\section{AS MUDANÇAS NO CAMPO DA EDUCAÇÃO}

De forma geral, as TIC estão sendo inseridas em diversos âmbitos da nossa sociedade. Essas ferramentas estão tornando-se, cada vez mais, parte indispensável da vida dos indivíduos. Elas estão presentes na intermediação de uma série de tarefas do nosso dia a dia e vêm modificando as nossas formas de agir, pensar e viver. Na atual conjuntura de mudanças estruturais em vários âmbitos da nossa sociedade, de introdução de TIC no mundo do trabalho e de uma grande valorização do conhecimento na contemporaneidade, como está a situação do campo da Educação em meio a esses processos?

Para Pierre Lévy (2010), o surgimento das TIC e da Cibercultura traz mudanças diretas na educação, na construção do saber e no aparecimento de uma inteligência coletiva. Segundo ele, "qualquer reflexão sobre o futuro dos sistemas de educação e de formação na cibercultura deve ser fundada em uma análise prévia da mutação contemporânea da relação com o saber". (LÉVY, 2010, p. 159). Dessa forma, o autor nos apresenta três constatações sobre essa relação: a primeira, é sobre a velocidade da renovação de saberes; a segunda é sobre a nova natureza do trabalho; e por último, a terceira constatação é sobre o ciberespaço servir como suporte para tecnologias intelectuais que aumentam, exteriorizam e modificam diversas funções cognitivas dos seres humanos. (LÉVY, 2010).

Sobre a evolução dos saberes, na atualidade ela ocorre em um ritmo extremamente rápido. Para Lévy (2010), a maioria dos saberes que adquirimos durante nossa formação profissional, ao final da nossa vida (ou até bem antes) já estarão ultrapassados. A necessidade de formação qualificada e de estar constantemente atualizado em relação às mudanças faz com que as pessoas busquem cada vez mais qualificação profissional.

Já em relação à nova natureza do trabalho, as mudanças ocorridas no mundo do trabalho com a inserção de TIC e de políticas neoliberais com o objetivo de aumentar a produtividade e a flexibilização das atividades, acabaram chegando no campo da educação e tendo reflexos diretos no trabalho docente. Através de um discurso modernizador da educação, os governos vêm incentivando e introduzindo novas tecnologias nos espaços de ensino. Esse processo, por sua vez, acaba exigindo mudanças nas metodologias de ensino. Nesse contexto, cobram-se mudanças na formação docente, mais qualificação desses profissionais para inserir as TIC no seu processo de trabalho. (KENSKI, 1999; FIDALGO; OLIVEIRA; FIDALGO, 2009; LÉVY, 2010).

Não é possível pensar na prática docente sem pensar, antecipadamente, na pessoa do docente que está em pauta e em sua formação que, [...] não se dá apenas durante o seu percurso nos cursos de formação de professores, mas, permanentemente, durante todo o seu caminho profissional, dentro e fora da sala de aula. (KENSKI, 1999, p. 49-50).

Na contemporaneidade, os profissionais da educação precisam estar atualizados em relação às mudanças tecnológicas para que eles saibam não apenas utilizá-las, como também decidir a melhor forma de inseri-las ou não nos processos de ensino e aprendizagem dentro da sala de aula. Autores como Kenski (1999; 2003; 2008), Prensky (2001), Bauman (2013) e Lévy (2010), apontam para a necessidade de uma mudança de postura do docente, pois 
agora as formas de aprender e ensinar vêm mudando radicalmente com as novas tecnologias. Nesse contexto, o professor deixa de ser aquele detentor do monopólio do saber e tem a função de ser uma espécie de colaborador do processo educativo, um incentivador da inteligência coletiva, auxiliando seus alunos na melhor forma de se obter informação e conhecimento. (LÉVY, 2010; BAUMAN, 2013).

Com a valorização da informação e do conhecimento na nossa sociedade, começa a existir uma verdadeira corrida das instituições de ensino, com o objetivo de se prepararem para dar conta das mudanças tecnológicas e do aumento da demanda de ensino.

\begin{abstract}
Os sistemas educacionais encontram-se hoje submetidos a novas restrições no que diz respeito a quantidade, diversidade e velocidade de evolução dos saberes [...]. As universidades transbordam [...]. Quase metade da sociedade está, ou gostaria de estar, na escola. (LÉVY, 2010, p. 171).
\end{abstract}

Para Lévy (2010), duas grandes mudanças precisam ocorrer nos sistemas de educação e de formação: a primeira tem a ver com a pedagogia (pois é preciso criar um novo estilo de pedagogia que favoreça os novos tipos de aprendizagens: tanto as personalizadas quanto as coletivas em rede); a segunda, é sobre a importância do reconhecimento dos saberes não acadêmicos para a construção do conhecimento coletivo. Dessa forma, Pierre Lévy (2010) ressalta que é preciso buscar soluções para que todos possam ter acesso ao conhecimento.

\begin{abstract}
Não será possível aumentar o número de professores proporcionalmente à demanda de formação que é, em todos os países do mundo, cada vez maior e mais diversa. Será necessário, portanto buscar encontrar soluções que utilizem técnicas capazes de ampliar o esforço pedagógico dos professores e dos formadores. (LÉVY, 2010, p. 171).
\end{abstract}

Em meio a esse contexto, a EAD aparece como uma das soluções para esse problema de demanda educacional. Devido ao fato desse modelo de ensino se utilizar de dispositivos audiovisuais e multimídias, além de outras facilidades disponíveis no ciberespaço, ele é bem mais barato e possui maior alcance que os métodos tradicionais de ensino. Mas essa crescente demanda quantitativa do ensino deve ser acompanhada de uma intensa mudança qualitativa na formação. Lévy alerta que a "simples massificação da oferta seria uma resposta 'industrialista' ao modo antigo, inadaptada à flexibilidade e à diversidade necessárias de agora em diante". (LÉVY, 2010, p. 172).

No atual contexto, a lógica produtivista e os processos de flexibilização do Mundo do Trabalho acabam afetando também a figura dos docentes. A exigência de produtividade aliada à flexibilização do trabalho que as TIC possibilitam e a diminuição dos salários dos professores, vêm contribuindo para o processo de precarização no trabalho docente. (LEMOS, 2011).

Uma nova realidade produtiva e de consumo se consolida com os processos de globalização e novos hábitos se instauram a partir da lógica das redes e da sociedade da informação e comunicação. Seguindo essa lógica, o professor, como um elo de ligação entre sociedade e os processos educacionais, vê seu trabalho sendo totalmente reconfigurado e flexibilizado, ao mesmo tempo em que, nos mesmos moldes de trabalhadores de outros setores, sente-se explorado na forma de seu trabalho imaterial e em sua capacidade intelectual, trazendo novos desafios, receios e anseios sobre seu futuro profissional. (KALLAJIAN, 2012, p. $39)$. 
Em suma, os processos capitalistas da sociedade da informação e do surgimento e de uma Cibercultura, vêm ocasionando e exigindo mudanças profundas no âmbito educacional. A valorização do conhecimento, no atual contexto, impulsiona uma grande corrida da sociedade em busca de uma melhor formação e qualificação para estar preparada para o mercado de trabalho. Isso, por sua vez, acaba ocasionando uma profunda mudança em toda a estrutura educacional para que ela dê conta do aumento da demanda de ensino.

Em meio a esses processos, o trabalho do docente passa por uma série de reconfigurações, as quais tem como base, a exigência de um profissional mais qualificado, polivalente, flexível e produtivo. Para aumentar a produtividade desse profissional e flexibilizar os processos de trabalho, as instituições de ensino fazem uso cada vez mais intenso de novas tecnologias.

\section{O USO DE TIC EM SALA DE AULA: OPINIÃO DE DOCENTES E DISCENTES}

A pesquisa de campo deste trabalho foi realizada no Bloco A, local onde são realizadas as aulas do curso de Ciências Sociais e no Instituto de Filosofia e Ciências Humanas (IFCH), do qual a Faculdade de Ciências Sociais (FACS) faz parte.Ambos se localizam no campus básico da UFPA, em Belém do Pará. No período da pesquisa de campo, chegamos a acompanhar aulas com as turmas do curso em questão, com o objetivo de observar melhor as dinâmicas inerentes à presença das TIC dentro das salas de aula. Nesse contexto, foram feitas diversas anotações em diário de campo, conversamos informalmente com docentes e discentes e, por fim, entrevistamos esses dois grupos de sujeitos para saber qual é a opinião deles em relação ao uso de TIC no ambiente acadêmico, em especial dentro da sala de aula, e como essas novas tecnologias vêm intermediando a relação entre eles.

A partir disso, foi possível analisar como docentes e discentes do curso de Ciências Sociais da UFPA estão lidando com o uso das TIC dentro das salas de aula e, consequentemente, como isso tem influenciado na relação entre eles e os discentes dentro da sala de aula. As abordagens aos docentes e discentes, para eles responderem às perguntas, eram realizadas geralmente ao término das aulas. Houve alguma resistência no início por parte de alguns docentes e discentes para conceder as entrevistas; mas de forma geral, a maioria dos indivíduos abordados foi bastante receptiva e colaborou bastante para a conclusão dessa pesquisa.

\section{OS DOCENTES E O USO DE TIC EM SALA DE AULA}

Durante o período em que ocorreram as entrevistas semiestruturadas, foram entrevistados 12 dos 36 docentes que estavam em atividade e que eram ligados a FACS no período da pesquisa.Dos entrevistados, todos revelaram que seus alunos costumam utilizar algum tipo de TIC durante as aulas, principalmente, o smartphone que é bastante popular entre os estudantes. Durante as observações de campo foi possível perceber que vários docentes fazem uso de recursos multimídias para ministrar suas aulas.

Em geral, esses recursos são usados em substituição a alguma ferramenta tradicional da sala de aula, no processo de ensino. Normalmente esses recursos são utilizados para passar slides ou algum filme relacionado ao tema da aula em questão. A partir disso, é possível ressaltar que os docentes vêm 
fazendo cada vez mais uso dessas novas tecnologias dentro da sala de aula, inserindo-as no processo educacional, mas geralmente essa inserção se dá de forma tradicional, sem ocasionar mudanças significativas na estrutura da aula. Os modelos de ensino hierárquicos e expositivos, onde o docente transmite conteúdo e os discentes apenas absorvem como sujeitos passivos no processo de aprendizagem, ainda persistem de forma bastante clara.

Durante as entrevistas foi perguntado aos docentes se eles utilizam TIC durante as aulas como uma ferramenta de auxílio no ensino.Assim, cerca de $25 \%$ dos docentes disseram que utilizam TIC para ministrar suas aulas. Em geral, eles ressaltaram a importância e a necessidade do professor de se adaptar às novas tecnologias e as mudanças que elas ocasionam. Como disse um dos docentes entrevistados: "O professor não pode ser um dinossauro, ele tem que saber se adaptar aos novos tempos, ele não pode ficar preso no passado" (informação verbal) ${ }^{4}$.

Em contrapartida, $75 \%$ dos docentes entrevistados, responderam que não utilizam nenhum tipo de TIC para auxiliar suas aulas. A maioria deles ressaltou que um dos principais fatores para eles não fazerem uso de TIC nas aulas é a falta de formação pedagógica e tecnológica deles para inserir essas ferramentas de forma que elas venham a ajudá-los no processo de ensino e aprendizagem. Além disso, parte deles também reclamouda falta de amadurecimento dos discentes que, segundo eles, geralmente usam as TIC durante a aula para realizar outras atividades não relacionadas ao contexto situacional, como por exemplo, jogar, acessar redes sociais e mandar mensagens pelo Whatsapp ${ }^{5}$.

Castells (2016) e Kumar (2006) ressaltam que no contexto da Sociedade da Informação, surge a necessidade de um novo tipo de trabalhador para desempenhar as novas funções exigidas no mercado de trabalho. Esses trabalhadores precisam de um alto grau técnico e de conhecimento teórico para utilizar as novas ferramentas tecnológicas. Isso por sua vez, requer grandes períodos de treinamento e educação.

Nesse contexto, Prensky (2001), Kenski (2003) e Lévy (2010), enfatizam que, à medida que as TIC adentram a nossa sociedade e, consequentemente, os espaços de ensino, elas têm revolucionado culturalmente e socialmente as formas de obter informação e conhecimento. Nesse cenário de mudanças, novas ferramentas vêm sendo disponibilizadas para a educação, criando novos caminhos para a aprendizagem, onde aquele modelo de ensino hierárquico, no qual o professor transmite conhecimento e os alunos apenas absorvem como sujeitos passivos no processo de aprendizagem, no atual estágio da nossa sociedade vêm se mostrando ultrapassado, pois um novo modo de ensinar e aprender está emergindo na atualidade, onde todos trocam informações e conhecimentos em tempo real dentro e fora das salas de aula. Dessa forma, torna-se cada vez mais necessário repensar a formação docente e adaptá-la à nova realidade educacional. (PRENSKY, 2001; KENSKI, 2003; LÉVY, 2010).

Essa nova pedagogia estimula os sujeitos a seguir novos caminhos, novos métodos e práticas que são extremamente valorizadas na Sociedade da Informação. A aprendizagem colaborativa estimula o indivíduo a pensar coletivamente, além de desenvolver suas habilidades pessoais. Nessa nova sociedade, a aprendizagem é estimulada por diversos meios e as instituições de ensino precisam estar atentas a isso, para que elas estejam em sintonia com as tecnologias e pessoas desse novo paradigma informacional. Kenski (1999) ressalta que é preciso fornecer aos docentes a formação, o tempo e a oportunidade para que eles aprendam as utilidades técnicas e metodológicas das TIC de modo que construam um conhecimento crítico sobre elas para decidir a melhor forma de inseri-las ou não no processo de ensino e aprendizagem. 
$\mathrm{Na}$ atualidade, é preciso que o docente saiba lidar com as novas tecnologias, que saiba manuseá-las e que possua o mínimo que seja de conhecimento técnico. É imprescindível que ele esteja sempre se atualizando de forma contínua para acompanhar o ritmo dessas mudanças tecnológicas que consequentemente acabam refletindo em seu trabalho dentro e fora da sala de aula, para que isso ocorra, uma atualização na formação desses profissionais precisa ser realizada por parte dos governos e suas políticas educacionais (BAUMAN, 2013).

[...] os professores precisam se atualizar, participar de eventos e cursos, ler pesquisas que abordem o assunto, estudar autores que promovam discussões atuais sobre o uso de redes sociais na educação, conhecer as redes sociais que permeiam o cotidiano dos jovens, criar possibilidades de uso das redes em sua ação docente.MORAES; GOMES, 2014, p. 6).

A partir disso, foi perguntado aos docentes se eles permitem que seus alunos usem alguma TIC dentro da sala de aula. As respostas foram as seguintes: Cerca de $75 \%$ dos docentes disseram que não permitem que seus alunos utilizem TIC durante as aulas. Em contrapartida, $25 \%$ dos docentes entrevistados disseram que permitem que seus alunos utilizem essas novas tecnologias durante a aula, pois muitos alunos utilizam-nas para ler textos, fazer downloads dos textos relacionados à aula e realizar pesquisas rápidas sobre o assunto da aula. Vários deles, inclusive, disseram que disponibilizam os textos da aula no SIGAA $^{6}$ para que os alunos realizem os downloads do material e possam economizar dinheiro, já que dessa forma, não precisam tirar xerox. Fato que foi confirmado e elogiado bastante pelos alunos.

Nesse contexto, foi perguntado aos docentes, durante as entrevistas, se eles são a favor ou contra a regulação ou proibição do uso de TIC em sala de aula.Cerca de $50 \%$ dos docentes entrevistados são totalmente contra a proibição ou limitação do uso de TIC em sala de aula. Já 33\% dos docentes entrevistados são a favor de estabelecer limites ao uso de TIC durante as aulas. Enquanto, $17 \%$ deles são a favor da proibição total do uso desses aparelhos dentro de sala. A maioria dos docentes ressaltaram a importância de o aluno utilizar essas ferramentas em sala de uma forma consciente e voltada para o aprendizado. Mas segundo eles, infelizmente, muitos alunos usam essas novas tecnologias durante as aulas para vários assuntos não relacionados ao ensino-aprendizagem.

Durante as entrevistas, foram vários os exemplos dados pelos professores: alguns reclamaram que os estudantes insistem em atender o smartphone dentro da sala de aula, o que atrapalha o desenvolvimento da aula; bem comousar a internet para assuntos não relacionados ao conteúdo didático ministrado em sala. Em vários relatos dos professores, eles reclamam que muitos alunos não possuem maturidade para utilizar,de forma adequada dentro da sala de aula, essas ferramentas voltadas para a aprendizagem.

\footnotetext{
"Eu sinto que os alunos da graduação ainda não sabem usar essas tecnologias direito. Eu percebo que eles têm muita dificuldade pra utilizar essas ferramentas voltadas pro contexto da aula, de pesquisar, ler, etc. Eles são muito hábeis na comunicação instantânea, pra redes sociais [...]. No início me incomodava ver alunos usando celular na aula, mas agora eu deixo de lado. A única coisa que me incomoda é o celular tocando. Quando eu entro em sala de aula, eu dou um recado, não é uma ordem. Eu falo 'vou colocar meu celular em modo avião'. Quem quer fazer o mesmo, que faça; se não quiser ok, eu também não vou ficar me incomodando". (Informação verbal) ${ }^{7}$.
}

Dessa forma, é possível perceber que existem conflitos entre docentes e discentes relacionados ao uso de TIC, mas percebe-se também que alguns desses conflitos também vêm sendo combatidos por esses sujeitos ao longo do 
tempo, bem como a cultura do uso do SIGAA, que apesar de ainda ser incipiente, vem se desenvolvendo e crescendo aos poucos entre esses indivíduos. Em geral, o uso de TIC entre os sujeitos investigados é bastante frequente e é uma realidade dentro da sala de aula. Apesar dos conflitos provenientes do uso de TIC em sala de aula, da inserção dessas ferramentas na aprendizagem ou da proibição delas durante as aulas, é possível observar uma cibercultura se desenvolvendo entre os indivíduos investigados.

\section{O USO DE TIC EM SALA DE AULA POR PARTE DOS DISCENTES}

Durante a observação de campo, foi possível constatar que é muito grande entre os discentes o uso de TIC, principalmente, do smartphone. Além disso, foi possível perceber, mesmo que em menor número, tablets e notebooks sendo utilizados dentro da sala de aula por vários discentes. Isso apenas confirma que as TIC chegaram para ficar, e que é preciso fazer com que esses estudantes, que são futuros professores e pesquisadores, utilizem essas ferramentas tecnológicas de forma consciente e voltada para fins relacionados à pesquisa e ao ensino.

Hoje em dia, muito se fala da grande familiaridade dos mais jovens com relação ao uso de tecnologias digitais e informáticas, em especial, devido à facilidade desses indivíduos de conseguirem acompanhar o ritmo das inovaçõesdesse novo paradigma tecnológico. Autores como Prensky (2001), Serres (2013) e Lévy (2010) em alguns de seus trabalhos, ressaltaram o grande potencial das novas gerações para assimilar as mudanças tecnológicas da contemporaneidade e evidenciaram o fato desses sujeitos através do contato com as TIC em rede, sofrerem uma série de mudanças não só nos seus hábitos, padrões e costumes, mas também mudanças cognitivas em relação aos indivíduos de outras gerações.

A partir da observação de campo, foi perguntado aos estudantes nas entrevistas, se eles costumam utilizar algum tipo de TIC durante as aulas. Em suma, dos 34 discentes entrevistados, 14,70\% afirmaram que não usam nenhum tipo de TIC durante as aulas, porque acham que o uso de aparelhos eletrônicos durante a aprendizagem, se não forem inseridos no contexto da aula, pode atrapalhar a aprendizagem deles. Por outro lado, 85,30\% dos alunos entrevistados responderam que fazem uso de algum tipo de TIC na sala de aula. Eles disseram que utilizam principalmente o smartphone para acessar as mídias sociais, verificar e-mails e realizar algum tipo de pesquisa relacionada aos assuntos trabalhados na aula.

Vários estudantes revelaram que, durante as aulas, costumam utilizar essas novas tecnologias, bem como a internet wifi do campus, para fazer downloads e ler os textos que serão trabalhados pelos professores em sala de aula. Segundo eles, é uma forma que encontraram de economizar dinheiro e utilizar essas ferramentas - principalmente o smartphone - de uma forma útil e voltada àsua aprendizagem. Alguns docentes, percebendo esse uso de TIC pelos alunos durante as aulas para ler os textos das disciplinas, começaram a deixar o material das suas disciplinas, que são trabalhados durante o semestre, no SIGAA ou nos e-mails coletivos das turmas.

Devido ao uso de TIC pela maior parte dos discentes dentro da sala de aula, foi perguntado a eles se já foram chamados à atenção ou advertidos de alguma forma pelos professores por causa disso. Assim, cerca de 70,6\% dos entrevistados responderam que nunca foram advertidos ou chamados a atenção de alguma forma pelos professores devido ao uso de TIC em sala de aula. Já 
29,4\% dos discentes disseram que já foram advertidos pelos docentes devido a utilização de TIC em sala. Foi ressaltado por eles, que são poucos os docentes que chamam a atenção diretamente dos discentes, pois muitos preferem advertir a turma inteira, de uma forma geral. Mas, segundo eles, já houve casos de alguns professores pararem a aula, dizendo que só retornariamà explicação do conteúdo didático se o aluno guardasse o aparelho ou se retirasse da sala. Isso evidencia que existe uma tensão entre alguns docentes e discentes em relação ao uso de TIC em sala de aula.

Foi possível constatar na observação de campo - e também foi ressaltado pelos estudantes nas entrevistas - que alguns docentes utilizam algum tipo de TIC para ministrar suas aulas, em geral, recursos multimídias, como datashow, caixas de som e notebook. O uso dessas ferramentas por parte dos docentes é quase sempre formal e tradicional, sem nenhum tipo de novidade na aprendizagem. Geralmente os professores usam esses recursos para passar slides ou algum filme durante a aula. Além disso, muitos discentes denunciaram a falta de incentivo por parte de alguns docentes, de fazer com que os estudantes aprendam a utilizar as TIC de uma forma pedagógica. Essa reclamação dos discentes é relevante, pois como o curso de Ciências Sociais além de ser de bacharelado, também é de licenciatura, esses futuros profissionais deveriam, teoricamente, estar sendo preparados para saber agir diante da nova realidade social e, em especial, educacional, já que a presença de TIC nas salas de aula na atualidade vem tornando-se uma realidade em diversos lugares do mundo.

Segundo Moraes e Gomes (2014), existe certa “[...] urgência em repensar a estrutura e o funcionamento dos sistemas educacionais, bem como a organização dos currículos de formação em diferentes níveis, as metodologias, práticas e processos de mediação pedagógica" (p. 5). É por isso que, ao pensar na formação de futuros docentes e na formação continuada dos profissionais da educação, é necessário também analisar qual o papel das instituições de ensino em meio a tudo isso. (MORAES; GOMES, 2014).

[...] as instituições de ensino precisam estabelecer programas de formação continuada de professores, aliás, não apenas para o uso de tecnologias em educação, mas para toda a ação pedagógica que é promovida pelo professor e que deve estar em consonância com o contexto atual dos estudantes, alicerçadas em uma proposta pedagógica que estimule e provoque um movimento ensino-aprendizagem colaborativo, onde os estudantes construam o conhecimento coletivamente. (MORAES; GOMES, 2014, p. 6).

$\mathrm{Na}$ atualidade, as TIC vêm sendo inseridas nos mais diversos setores da nossa sociedade e na educação não é diferente. As instituições educacionais, em grande parte, estão tentando ao longo dos últimos anos, inserir algumas ferramentas tecnológicas com o objetivo de modernizar os processos de ensino. Mas, segundo Kenski (2008), esse processo vem se desenrolando de forma errada, pois todo o potencial de estimular e ampliar a comunicação entre os sujeitos participantes do processo educativo vem sendo limitado pelo uso restrito dessas ferramentas nos espaços formais de educação.

Nesse contexto, durante as entrevistas, os discentes revelaram que alguns docentes proíbem o uso de TIC dentro da sala de aula. Uma aluna durante a entrevista relatou que " [...] alguns professores mandam os alunos desligarem ou guardarem qualquer aparelho eletrônico que esteja sendo utilizado em sala de aula, por achar que os alunos só usam esses aparelhos para acessar as redes sociais" (informação verbal) ${ }^{8}$. Segundo eles, alguns professores proíbem, pois acham que o uso dessas tecnologias durante a aula pode atrapalhar a aprendizagem. Assim, mesmo muitos alunos concordando que o uso de TIC para assuntos 
eações que não fazem parte do contexto da aula pode atrapalhar a aprendizagem, todos se mostraram contra a proibição dessas novas tecnologias dentro da sala de aula, pois, segundo eles, a proibição delas é um retrocesso, já que elas estão se mostrando de muita utilidade para a maioria dos alunos que as utilizam para fazer pesquisas rápidas relacionadas ao conteúdo da disciplina, ler e baixar textos durante a aula.

O fato de todos os discentes se demostrarem contra a proibição do uso de TIC em sala de aula, deixa implícito uma espécie de consenso entre os estudantes de que a presença dessas tecnologias tanto dentro quanto fora da sala de aula é inevitável, e que elas devem ser integradas para ajudar nas atividades acadêmicas. Ignorar essa realidade é virar as costas para todas as possiblidades que essas ferramentas podem proporcionar. Se utilizadas de forma consciente e integradas ao contexto do ensino, elas podem vir a contribuir de forma decisiva para o desenvolvimento de uma ampliação na comunicação e o aumento da qualidade da aprendizagem dentro da sala de aula. (KENSKI, 2008).

Foi perguntado aos discentes, se eles acham que os docentes da FACS deveriamutilizaras TIC como ferramentas pedagógicas.A grande maioria dos entrevistados, $88,25 \%$ responderam que sim, que acham que os docentes do curso de Ciências Sociais deveriam utilizar as TIC como ferramentas de ensino para auxiliá-los no contexto da aula e do ensino-aprendizagem. Enquanto isso, $11,75 \%$ responderam que não.

As inovações tecnológicas como a internet, por exemplo, estimulam e ampliam os processos comunicacionais entre os indivíduos. Como o processo educativo é basicamente comunicacional e necessita da intensa participação de todos os sujeitos envolvidos, o uso dessas ferramentas nesse processo pode desempenhar um papel fundamental, mas infelizmente elas vêm sendo utilizadas de forma restrita e pragmática. Isso fica bem claro quando governantes responsáveis por políticas educacionais referem-se à internet, por exemplo, como "a lousa do futuro" ou aos tablets e notebooks como "os cadernos do futuro". (KENSKI, 2008).

Em síntese, aspotencialidades das novas ferramentas tecnológicas juntamente com a internet, que configuram as relações de espaço e de tempo e ampliam o poder de comunicação dos seres humanos, não têmsido devidamente exploradas pelos indivíduos participantes do processo educativo. Apesar de todas as mudanças, a flexibilidade e os formatos distintos que essas tecnologias apresentam - elas são apresentadas como algo veloz e de grande alcance - mas são utilizadas de forma previsível e fisicamente limitadas. (KENSKI, 2008).

Durante as entrevistas, foi ressaltado, que poucos docentes integram o uso de TIC em suas aulas. Além disso, muitos discentes denunciaram a falta de estrutura das salas de aula, criticaram a depredação do bloco de aulas, do descaso da instituição em não fornecer condições nem ferramentas adequadas para melhorar a aprendizagem deles. Eles também reclamaram da falta de incentivo por parte de alguns docentes de fazer com que eles aprendam a utilizar as TIC de uma forma pedagógica, inserida na aprendizagem. Outro ponto que os discentes ressaltaram foi alguns conflitos entre docentes e discentes referentes ao uso de TIC na sala de aula. Como relatou uma discente, "alguns professores mandam os alunos desligarem ou guardarem qualquer aparelho eletrônico que esteja sendo utilizado em sala de aula, por achar que os alunos só usam esses aparelhos para acessar redes sociais". (informação verbal) ${ }^{9}$.

De forma geral, foi possível constatar por meio de conversas informais com docentes e das entrevistas, que vários dos próprios docentes proíbem o uso dessas novas tecnologias dentro de sala de aula, pois acham que o acesso 
durante a aula pode atrapalhar ou que parte dos discentes utilizam-nas durante as aulas para fins não relacionados ao contexto da aula.

\section{A PRESENÇA DAS TIC NO COTIDIANO ACADÊMICO}

Através da observação de campo, conseguimos constatar que o dia a dia acadêmico é bastante marcado pela presença das TIC, sejam nos laboratórios e salas de informática, sejam nos processos de ensino e de comunicação, essas ferramentas estão cada vez mais intrínsecas no cotidiano de docentes e discentes, e no resto da comunidade acadêmica como um todo. Essas novas tecnologias vêm intermediando uma gama variada de situações que se estende desde o trabalho, do estudo até ao lazer, por exemplo. Isso demostra o crescimento da cultura digital dentro dos espaços acadêmicos. Nesse contexto, ressaltamos aqui alguns pontos que evidenciam quase que a imposição dessas tecnologias dentro do meio acadêmico.

Em relação aos docentes:

- Todos os professores que compõem o corpo docente da Faculdade de Ciências Sociais possuem e-mail.

- Todos os professores que compõem o corpo docente da Faculdade de Ciências Sociais têm Currículo Lattes, que é um padrão nacional de registro da vida acadêmica e atuação dos estudantes e pesquisadores de todo o país. Que é hoje adotado por quase todas as instituições de fomento, universidades e instituições de pesquisa do país.

- São os próprios professores que devem "lançar" os conceitos dos estudantes no Sistema Integrado de Gestão de Atividades Acadêmicas da UFPA.

- Vários docentes do curso de Ciências Sociais possuem perfis em mídias sociais como o Facebook, por exemplo.

- Vários docentes utilizam recursos multimídias para ministrar suas aulas.

Em relação aos discentes:

- Todos os discentes do curso de Ciências Sociais têm que acessar os seus dados acadêmicos, realizar matrícula ou o trancamento desta, através do SIGAA.

- Todos os discentes passam pelo ritual da escrita científica, desse modo, têm que adaptar sua produção acadêmica às regras da Associação Brasileira de Normas Técnicas (ABNT), que é o órgão responsável pela normalização técnica no país, fornecendo a base necessária ao desenvolvimento tecnológico brasileiro.

- Os discentes que são bolsistas de Iniciação Científica, por exemplo, precisam possuir um currículo lattes e mantê-lo atualizado.

- A grande maioria dos discentes do curso de Ciências Sociais possui e-mail e perfis em mídias sociais.

Esses pontos colocados acima, embora possam parecer óbvios, velam um processo, por mais básico que seja, de uma exigência de habilidade de manuseio e domínio de código da escrita com o emprego correto dos símbolos linguísticos das TIC, que docentes e discentes do curso de Ciências Sociais 
devem possuir para estarem integrados as rotinas e demandas da academia. Não estar em consonância com essas habilidades, não atender a essas exigências implícitas para estar inserido no meio digital dentro do cotidiano acadêmico, é sinal não só de uma exclusão digital, como também de uma exclusão social dentro da academia, já que muitas informações são compartilhadas por meios digitais e quem não está inserido nesse meio, acaba muitas vezes ficando à margem de processos importantes dentro da academia.

O maior desafio é a conscientização de que esses processos da Era digital, das novas tecnologias e tudo o que elas acarretam, estão em constantes mudanças. Assim, não só os indivíduos, mas as instituições sociais e a sociedade como um todo precisam estar atentas e tentar acompanhar e compreender essas mudanças, para conseguir tirar o melhor proveito delas em prol do desenvolvimento econômico e social (KENSKI, 2008). Nesse contexto, as universidades possuem um papel fundamental, pois elas representam grandes centros de difusão saberes e fazeres entre os indivíduos e o seu poder de difusão pode se estender aos hábitos de uma cibercultura, que se manifesta através de uma crescente comunicação mediada por computadores (CMC), onde os sujeitos inseridos nesse meio trocam informação, conhecimentos, documentos, experiências. "[...] Parte considerável das comunicações que acontecem na rede é, em geral, espontânea, não organizada e diversificada em finalidade e adesão". (CASTELLS, 2016, p. 437). Esses hábitos, após serem adquiridos pelos indivíduos no meio acadêmico, podem ser difundidos para o resto da sociedade.

\section{OS LOCAIS DE ACESSO A INTERNET DISPONIBILIZADOS PELA UFPA}

No Instituto de Filosofia e Ciências Humanas (IFCH), do qual a Faculdade de Ciências Sociais faz parte, existe um laboratório de Informática que é para o uso comum dos discentes vinculados a qualquer uma das cinco faculdades que compõem esse instituto. Em resumo, o laboratório de informática é extremamente importante devido ao fato de que uma parcela de alunos do curso de ciências sociais, por exemplo, não possuir um notebook ou acesso à internet em casa. Dessa forma, o laboratório de informática, bem como os outros espaços dentro da instituição que fornecem máquinas e acesso à internet, tornam-se valiosíssimos para esses indivíduos, já que é uma das poucas formas que eles possuem de estarem inseridos no meio digital.

Nesse contexto, é bastante comum a presença de alunos nesse laboratório de informática, bem como no infocentro e nos cybers espalhados pelo campus universitário. No entanto, o uso do laboratório de informática do IFCH é um uso limitado, uma vez que não é permitido que seja acessado mídias sociais como Facebook e Twitter, por exemplo. Esse impedimento da utilização de mídias sociais representa uma limitação, devido ao fato de que vários processos comunicacionais, informativos e educacionais entre docentes e discentes, bem como entre a instituição e a comunidade acadêmica como um todo, ocorrem em mídias sociais.

$O$ relato de um discente durante as entrevistas deixa claro a importância do laboratório de informática do IFCH para alguns alunos do curso de ciências sociais que não possuem acesso à internet em casa e têm esse laboratório como único espaço para utilizar e se inserir no meio digital.

“A importância dele é enorme, é gigante. Esse laboratório é acesso à informação. Graças a ele, muita gente do curso que não tem computador ou internet em casa, pode ter acesso à informação, a eventos que tão 
acontecendo nesse exato momento. Então eu posso colocar filtros pra qualificar a informação, pra saber se aquilo é correto ou não, pra tentar entender as coisas de uma forma mais global, pra não ficar preso só no nosso mundinho, no nosso umbigo. É esse vai e vem, essa ida e volta entre o local e o global, graças a esse espaço, a essas novas tecnologias e à internet principalmente, abriram um mundo pra gente. Ele permitiu que a gente tivesse acesso a muita coisa, então agora a gente tem que saber como lidar todas essas informações, como filtrar essas informações todas, como qualificar elas" (Informação verbal) ${ }^{10}$.

Nos últimos anos vem sendo implantado o sistema Wireless (sem fio) - popularmente conhecido como wifi - no campus básico da Universidade Federal do Pará. A iniciativa é importante para inserção na dita sociedade informacional e a otimização das TIC, uma vez que o principal foco são as salas de aulas. De qualquer lugar de abrangência da cobertura do sinal, pode se ter acesso à internet de forma livre e gratuita, bastando ter um smartphone, tablet ou notebook que capture o sinal.

Alguns teóricos da área da comunicação como Santaella (2008) e Lemos (2009), por exemplo, abordam sobre um novo estágio da Cibercultura neste início de século, um processo de evolução que se caracteriza com a popularização da internet móvel e das novas tecnologias, que possibilitam que os indivíduos estejam ainda mais conectados, já que agora não precisam mais ficar fixos em um local para adentrar o ciberespaço. Essa nova fase da Cibercultura provoca profundas mudanças na configuração do espaço e do tempo, e é classificada como a Era da Conexão ou Cultura da Mobilidade. (SANTAELLA, 2008; LEMOS, 2009).

A cultura da mobilidade entrelaça questões tecnológicas, sociais, antropológicas. Para a comunicação, a mobilidade é central já que comunicar é fazer mover signos, mensagens, informações, sendo toda mídia (dispositivos, ambientes e processos) estratégias para transportar mensagens afetando nossa relação com o espaço e o tempo. (LEMOS, 2009, p. 28).

Durante conversas informais com professores e alunos, alguns desses indivíduos reclamaram do sinal wifi do campus. Foram vários os relatos dizendo que "o sinal só pega quando quer" (informação verbal) ${ }^{11}$. É verdade que ainda existem áreas do campus em que o sinal não pega (chamado de "pontos cegos").A cobertura do sinal aindaprecisa melhorar bastante, pois durante o período em que estava sendo realizada a pesquisa de campo, foi possível constatar que existem locais em que o sinal wifi não funciona, além de, em outros momentos, ele ser bastante lento.

"A universidade cresceu muito nos últimos anos. Mas em questão de
espaços e logística ela ainda tem muito a melhorar. Um problema muito
sério é [...] a falta da capacidade da universidade de fornecer mais labo-
ratórios de informática, aumentar o número de máquinas e tentar acabar
com as constantes quedas e lentidão do wifi [...]" (Informação verbal) ${ }^{12}$.

Tanto docentes quanto discentes também reclamaram das constantes quedas e lentidão da internet wifi. Para solucionar esses problemas, ao longo dos últimos anos a instituição vem tentando ampliar o sinal wifi e aumentar a velocidade, já que as reclamações sobre a ausência de sinal em determinados lugares do campus e sobre a lentidão da velocidade da internet, serem constantes. Assim, recentemente a UFPA divulgou por meio de suas mídias sociais, que a cobertura do sinal no campus havia sido ampliada para melhorar o acesso à internet da comunidade acadêmica. 
Já em relação ao problema da velocidade da internet disponibilizada no campus, recentemente a UFPA divulgou nas suas mídias sociais que havia aumentado também a velocidade do sinal wifi no campus de 1 Giga para 10 Gigas. Com essa expansão de velocidade, segundo a instituição, os benefícios para a comunidade acadêmica são enormes, pois com a internet 10 vezes mais rápida, aumenta a capacidade da instituição de prover serviços básicos como downloads de arquivos até serviços de alta demanda como transmissões ao vivo, cobertura de eventos, entre outros. Com essa mudança, tudo que envolve acesso a tecnologias de informação e comunicação e internet na Universidade é beneficiada. (SHINOHARA, 2017).

Inicialmente a implantação de um sistema wireless na universidade - e mais tarde, o aumento da cobertura e a expansão da velocidade do sinal fornecido - é de uma utilidade enorme e representa um grande benefício para toda a comunidade acadêmica. É mais facilidade para a realização de trabalhos e pesquisas dentro e fora da sala de aula - e de socialização e conexão com o mundo, já que se pode acessar as mídias sociais livremente.

O problema das iniciativas referentes à introdução de TIC nas instituições de ensino, é que esse processo está se dando de forma quantitativa, sem se atentar para os aspectos qualitativos desse contexto. Dessa forma, as políticas de incentivo a modernização da educação, na maior parte das vezes, são baseadas apenas na inserção de TIC dentro dos espaços educacionais, sem se atentar que, para existir um verdadeiro salto qualitativo na educação é preciso agir conjuntamente com os profissionais da educação e qualificá-los, fornecendo formação técnica e pedagógica atualizada, para que eles estejam preparados para utilizar essas ferramentas e decidir a melhor forma de inseri-las no processo de ensino. (LÉVY, 2010; KENSKI, 2008).

\section{CONSIDERAÇÕES FINAIS}

As transformações tecnológicas vividas pelos sujeitos na contemporaneidade representam não só a inserção de equipamentos e técnicas, mas também se manifestam na forma como os indivíduos estão vivendo e trabalhando essas transformações em suas relações cotidianas. Desse modo, as TIC estão presentes na nossa vida, no nosso trabalho e na nossa constituição como ser social. Assim, a importância desse trabalho se justifica pelo fato de que a presença dessas tecnologias é uma realidade que vem adentrando diversos setores da sociedade, reestruturando uma série de instituições sociais e modificando as nossas formas de ser, agir e pensar.

A partir do momento em que a informação e o conhecimento começam a ser vistas como extremamente importantes para o desenvolvimento do capitalismo, as universidades passam a sofrer uma série de reestruturações orientadas por organismos internacionais com o objetivo de aumentar a produção científica e tecnológica dentro da academia. Assim, esses espaços de ensino passam a ser orientados e geridos através de uma lógica empresarial onde é priorizada a introdução de TIC no trabalho com o objetivo de flexibilizar as atividades e aumentar a produtividade.

Nesse contexto, o desenvolvimento do presente estudo permitiu a análise sobre os desdobramentos ocasionados pela inserção de TIC no ambiente acadêmico, mais especificamente no curso de Ciências Sociais da UFPA. A partir dos resultados da pesquisa de campo, onde foram utilizados instrumentos como a observação direta e participante, o registro em diário de campo, bem como entrevistas semiestruturadas com docentes e discentes, foi possível iden- 
tificar e analisar ações formais e não formais realizadas por docentes e discentes referentes aos usos de TIC, além de identificar o que a UFPA vem fazendo para preparar a comunidade acadêmica para que ela esteja apta a utilizar as TIC no ambiente acadêmico.

Cabe ressaltar que uma parcela significativa dos estudos realizados sobre o uso de TIC nos espaços de ensino ressaltam apenas os aspectos positivos e quantitativos desse processo. Dessa forma, a contribuição acadêmica desta pesquisa se justifica devido ao fato de que ela buscou compreender não só os aspectos positivos, mas também os aspectos negativos relacionados ao uso dessas tecnologias nas instituições de ensino; além de abordar tanto sobre os aspectos quantitativos quanto os aspectos qualitativos desse processo. Através do estudo do caso específico do curso de Ciências Sociais da UFPA, tornou-se possível investigar melhor como vem sendo realizada a inserção e o uso dessas tecnologias no ambiente acadêmico e quais os desdobramentos oriundos desse processo. Em suma, podemos afirmar que este trabalho contribui para o panorama de discussões gerais sobre o uso de TIC nos ambientes acadêmicos por parte de docentes e discentes.

De forma geral, podemos ressaltar que a inserção de TIC nos ambientes acadêmicos, especificamente no trabalho de docentes e na relação entre eles e os discentes, possui vários aspectos positivos e negativos que foram sendo identificados e ressaltados ao longo desse trabalho. Assim, entre os aspectos positivos desse processo, podemos destacar o crescimento da cibercultura entre os sujeitos investigados e no meio acadêmico como um todo. Esse fato fica evidente através dos dados obtidos a partir da pesquisa de campo na universidade, revelando que esses sujeitos encontram-se cada vez mais inseridos no meio digital, utilizando as TIC e a internet para realizar diversas tarefas ligadas, principalmente, ao seu trabalho.

Podemos ressaltar que uso de TIC em sala de aula vem se configurando como uma realidade dentro da academia. Este fato foi constatado por meio da observação direta e participante e das entrevistas semiestruturadas, onde foi possível detectar que as TIC estão sendo utilizadas por grande parte dos alunos para realizar pesquisas e ler textos relacionados aos conteúdos trabalhados dentro de sala. Em relação ao uso dessas ferramentas na sala de aula por parte dos docentes, vários desses profissionais têm inseridoaos poucos essas ferramentas no contexto das suas aulas, mas esse uso, em geral, é bastante tradicional (normalmente, apenas substitui ferramentas pedagógicas tradicionais como a lousa, sem acrescentar grandes novidades na metodologia pedagógica utilizada por eles).

Além disso, a relação entre docentes e discentes tem sido permeada por diversos conflitos relacionados aos usos de TIC dentro da sala de aula e fora dela. Em geral, vários docentes ressaltaram nas entrevistas que seus alunos utilizam bastante as TIC em sala de aula, principalmente, o smartphone, fato que ficou comprovado durante a pesquisa de campo. Os conflitos se originam normalmente devido ao fato de que alguns docentes proíbem o uso de TIC em sala de aula por acharem que os discentes utilizam essas ferramentas em sala para assuntos não relacionados à aula (como mandar mensagem, acessar as mídias sociais e jogar no celular, por exemplo). Os alunos, por sua vez, cobram que os docentes se modernizem e insiram as TIC como ferramentas pedagógicas, pois o uso desses recursos por parte dos docentes, quando são utilizados, é geralmente de forma bastante pragmática e tradicional (como passar slides para não precisar utilizar o quadro).

Por fim, os resultados da pesquisa de campo também ressaltaram que a UFPA, por sua vez, está se esforçando- por meio da criação de salas de informá- 
tica, aumento da velocidade e ampliação do sinal de internet sem fio no campus, implantação de um novo sistema online para gerir as atividades acadêmicas, bem como inauguração de espaços que possuem recursos multimídias, máquinas e instalações adaptadas para o uso de TIC -emadequar ainfraestrutura física da instituição para que ela esteja de acordo com as exigências da Era Digital. Além disso, a universidade, ao longo do tempo, também tem tentado preparar a comunidade acadêmica, para que esteja apta a utilizar essas ferramentas e se inserir no contexto do ciberespaço. Vale ressaltar em relação a essa tentativa de qualificação da comunidade acadêmica por parte da universidade, que ela ainda é bastante incipiente e não abrange toda a demanda acadêmica, que cresce cada vez mais ao longo dos anos.

\section{NOTAS}

${ }^{1}$ Mestre em Sociologia pela Universidade Federal do Pará. Professor da rede pública do Estado do Pará.

${ }^{2}$ Doutora em Antropologia. Professora da Universidade Federal do Pará.

${ }^{3}$ Mestreem Antropologia pelo Programa de Pós-Graduação em Sociologia e Antropologia da Universidade Federal do Pará.

${ }^{4}$ Informação verbal concedida durante entrevista semiestruturada com docentes do curso de Ciências Sociais.

${ }^{5}$ Aplicativo de mensagens instantâneas.

${ }^{6}$ Sistema Integrado de Gestão de Atividades Acadêmicas é uma tecnologia web, responsável por gerir as atividades acadêmicas da Instituição. O SIGAA é centrado numa base de dados integrada, onde todos os sistemas compartilham uma base de dados comum, evitando, dessa forma, a replicação de dados, a redundância e a inconsistência na informação.

${ }^{7}$ Informação verbal concedida durante entrevista semiestruturada com docentes do curso de Ciências Sociais.

${ }^{8}$ Informação verbal concedida durante entrevista semiestruturada com discentes do curso de Ciências Sociais.

${ }^{9}$ Informação verbal concedida durante entrevista semiestruturada com discentes do curso de Ciências Sociais.

${ }^{10}$ Informação verbal concedida durante entrevista semiestruturada com discentes do curso de Ciências Sociais.

${ }^{11}$ Informação verbal concedida por discente durante conversa informal.

${ }^{12}$ Informação verbal concedida durante entrevista semiestruturada com docentes do curso de Ciências Sociais.

\section{REFERÊNCIAS}

BAUMAN, Zygmunt. Modernidade Líquida. Rio de Janeiro: Zahar, 2001. . Sobre Educação e Juventude: conversas com Ricardo Mazzeo/ZygmuntBauman. Rio de janeiro: Zahar, 2013.

CASTELLS, Manuel. A sociedade em Rede. São Paulo: Paz e Terra, 17. ed. 2016.

CENTRO DE TECNOLOGIA DA INFORMAÇÃO E COMUNICAÇÃO.

UFPA implanta sistema SIGAA na graduação. Universidade Federal do Pará, 2014.

FIDALGO, Fernando; OLIVEIRA, Maria Auxiliadora M; FIDALGO, Nara Luciene Rocha. A Intensificação do Trabalho Docente:tecnologias e produtividade. Campinas, SP: Papirus, 2009. 
HARVEY, David. Condição Pós-Moderna: uma pesquisa sobre as origens da mudança cultural. São Paulo: Edições Loyola, 13. ed. 2004.

KALLAJIAN, Gustavo Cibim. Implicações da Tecnologia Digital no Trabalho Docente de Ensino Superior. Uberaba, 2012.

KENSKI, Vani Moreira. Aprendizagem mediada pela tecnologia. Revista Diálogo Educacional, Curitiba, v. 4, n.10, p.47-56, set./dez. 2003.

. Educação e Comunicação: interconexões e convergências. Educ.

Soc., Campinas, v. 29, n. 104 - Especial, p. 647-665, out. 2008.

.Novas tecnologias, o redimensionamento do espaço e do tempo e os impactos no trabalho docente.Informática Educativa, v. 12, 1999.

KUMAR, Krishan. Da sociedade pós-industrial à pós-moderna: novas teorias sobre o mundo contemporâneo. Rio de Janeiro: Jorge Zahar, 2006.

LEMOS, André. Cultura da Mobilidade. Revista FAMECOS, Porto Alegre, n. 40, 2009.

LEMOS, Denise. Trabalho Docente nas Universidades Federais: tensões e contradições. CADERNO CRH, Salvador, v. 24, n. 01, p. 103-118, 2011.

LÉVY, Pierre. Cibercultura. São Paulo: editora 34, 3. ed. 2010.

MORAES, Ana Carolina de; GOMES, Kelly Aparecida. Redes Sociais na Educação: a importância da capacitação docente. VIII Simpósio Nacional da ABCiber, ESPM-SP - 3 a 5 de dezembro de 2014.

PRENSKY, Marc. Nativos Digitais, Imigrantes Digitais. De OntheHorizon (NCB University Press, Vol. 9 No. 5, Outubro 2001). Tradução do artigo "Digital natives, digital immigrants", de Marc Prensky. Tradução gentilmente cedida por Roberta de Moraes Jesus de Souza: professora, tradutora e mes-

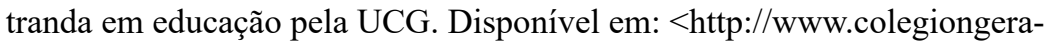
cao.com.br/novageracao/2_intencoes/nativos.pdf $>$. Acesso em: 29 set. 2016.

SANTAELLA, Lucia. Mídias locativas: a internet móvel de lugares e coisas. Revista FAMECOS, Porto Alegre, no 35, 2008.

SERRES, Michel. Polegarzinha. Rio de Janeiro: Bertrand Brasil, 2013.

SHINOHARA, Edielson. Novo link de dados expande a velocidade de internet na UFPA. Universidade Federal do Pará, 2016. Disponível em: <https:// ww2.ufpa.br/imprensa/noticia.php?cod=12323>. Acesso em: 01 nov. 2016.

VESCE, Gabriela EyngPossolli. As Mudanças no Mundo do Trabalho e o Discurso sobre Tecnologia no Contexto Universitário.EDUCERE, 2008. Disponível em: $<$ http://www.pucpr.br/eventos/educere/educere2008/anais/ pdf/569_400.pdf $>$. Acesso em: 06 out. 2016.

VIEIRA, Mariana. Aumenta a cobertura da rede sem fio no campus da universidade. Universidade Federal do Pará, 2017. Disponível em: <https:// portal.ufpa.br/index.php/ultimas-noticias2/176-aumenta-a-cobertura-da-rede-sem-fio-no-campus-da-universidade>. Acesso em: 29 jul. 2017. 